\title{
Bio-plastic Films Production from Feather Waste Degradation by Keratinolytic Bacteria Bacillus cereus
}

\author{
Wafa A. Alshehri ${ }^{1 *}$ (D), Ashjan Khalel ${ }^{2}$, Khaled Elbanna ${ }^{3,4}$ (D), \\ Iqbal Ahmad ${ }^{5}$ (D) and Hussein H. Abulreesh ${ }^{3}$ (D)
}

${ }^{1}$ Department of Biology, College of Science, University of Jeddah, Jeddah, Saudi Arabia.

${ }^{2}$ Department of Biology, Faculty of Science, King Abdulaziz University, Jeddah, Saudi Arabia.

${ }^{3}$ Department of Biology, Faculty of Applied Science, Umm Al-Qura University, Makkah, Saudi Arabia.

${ }^{4}$ Department of Agricultural Microbiology, Faculty of Agriculture, Fayoum University, Fayoum, Egypt.

${ }^{5}$ Department of Agricultural Microbiology, Faculty of Agricultural Sciences, Aligarh Muslim University,

Aligarh - 202 002, India.

\begin{abstract}
Plastic materials have become a necessity of human life especially in the packaging of food commodities and biomedical procedures. Bioplastic is emerging as an effective alternative to fossil oil-based materials to avoid the environmental hazards of the plastic industry. During this study, chicken feathers were used as a substrate to isolate keratin degrading bacteria. Among 14 identified isolates, Bacillus sp BAM3 was found to be the most promising isolate. Partial 16S rDNA analysis-based molecular characterization revealed it is a strain of Bacillus cereus. Bacillus Sp BAM3 can grow and produce keratinase in feathers containing basal medium as the sole carbon and energy source. The maximum keratinase production $(730 \mathrm{U} / \mathrm{ml})$ was achieved within $24 \mathrm{~h}$ under optimum reaction conditions. The optimized reaction $\mathrm{pH}$ and temperature were noted as 9.0 and $50^{\circ} \mathrm{C}$ for crude keratinase activity, respectively. The chicken feathers were used as a substrate in 2, 5, and $10 \mathrm{wt} \%$ glycerol to synthesize keratin-based bioplastic with keratinolytic bacterium Bacillus cereus BAM3. Bioplastic prepared from keratin with $2 \%$ of glycerol was found to possess good mechanical properties. Therefore, the results present a novel keratinolytic isolate of Bacillus cereus BAM3, which may have potential biotechnological applications in keratin hydrolysis processes. The development of keratin-based bioplastics possessing superior crystalline morphology requires further investigations to substitute fossil oil-based materials.
\end{abstract}

Keywords: Bacillus cereus, bio-plastic, keratinolytic bacteria, feather

*Correspondence: waalshehri@uj.edu.sa

(Received: March 01, 2021; accepted: April 05, 2021)

Citation: Alshehri WA, Khalel A, Elbanna K, Ahmad I, Abulreesh HH. Bio-plastic Films Production from Feather Waste Degradation by Keratinolytic Bacteria Bacillus cereus. J Pure Appl Microbiol. 2021;15(2): 681-688. doi: 10.22207/JPAM.15.2.17

(C) The Author(s) 2021. Open Access. This article is distributed under the terms of the Creative Commons Attribution 4.0 International License which permits unrestricted use, sharing, distribution, and reproduction in any medium, provided you give appropriate credit to the original author(s) and the source, provide a link to the Creative Commons license, and indicate if changes were made. 


\section{INTRODUCTION}

The plastic carrier bags gained popularity in the late $1970 \mathrm{~s}^{1}$. The environmental hazards of synthetic polymers have urged scientists to develop biodegradable alternatives from renewable polysaccharides $s^{2,3}$ proteins $^{4,5}$ and lipids ${ }^{6}$. The limited stock and rising prices of petroleum enhance the utility of bioplastic in the future. The traditional plastic products manufactured from fossil oil are non-biodegradable and thus are considered hazardous for terrestrial and marine environments. The plastic material used for the food packaging ends up in landfills whereas only $5.7 \%$ is recycled ${ }^{7}$. The usage of unpalatable animal parts including, viscera, heads, bones, legs, and feathers is increasing in the manufacturing of various products ${ }^{8}$. Feathers are particularly a potent source of developing biodegradable commodities. Keratin waste is rich in protein (90\%), nitrogen (15-18\%), and sulfur (2-5\%) $)^{9}$ A considerable amount of keratin waste especially feathers is produced during animal farming and trading. Keratin proteins are highly resistant to enzymatic lysis and chemical agents, as they contain multiple disulfide bonds $(\mathrm{S}-\mathrm{S})^{10}$. However, numerous keratinolytic microorganisms have been documented including the members of the genus Bacillus, Vibrio, Serratia, actinomycetes ${ }^{11,12}$, and recombinant strain of Bacillus ${ }^{13}$. Chrysosporia microfungi belonging to the genus Chrysosporium, also known as geophilic dermatophytes, are specialized in the degradation of keratin proteins. The occurrence and growth of keratin-degrading microorganisms depend upon the enrichment of keratin in the soil. The chicken feather-based keratin protein, either alone or in combination with synthetic or natural polymers, has diverse applications in manufacturing films, sponges, and fibers $^{2,14,15,16,17}$. The keratin of chicken feather ${ }^{4,8,11,17}$ can be applied to develop biodegradable and environmentally safe bioplastic ${ }^{18}$. A recent study has reported that keratolytic bacteria degraded chicken feathers into keratin micro-particles to produce bioplastic ${ }^{19}$. The present study focuses to assess the mechanical properties and ability of keratinolytic bacterium to produce chicken feathers-based bioplastic film at various glycerol concentrations. The study can facilitate the development of commercial bioplastic films in the future.

\section{MATERIAL AND METHOD} Isolation of keratinolytic bacteria with chicken feathers

Isolation and screening of the keratolytic bacteria were performed by suspending the samples in feather meal broth medium as described by Agrahari and Wadhwa ${ }^{20}$. One gram of the soil sample and poultry or feather waste was added in $50 \mathrm{ml}$ of the medium. All flasks were incubated at $37^{\circ} \mathrm{C}$ for $7-14$ days. Then, $1 \mathrm{ml}$ broth of each was transferred to Feather Meal Agar Medium plates and incubated at $37^{\circ} \mathrm{C}$ for 2 days. The developed colonies were purified by repeated streaking to obtain pure culture on Nutrient agar plates.

Chicken feathers were used as a substrate to isolate keratinolytic bacteria in keratin medium. Chicken feathers were obtained from the Al-Rayan poultry farm, Jeddah, Saudi Arabia. Feathers were prepared according to Tork et al., 201021 with minor modification. Feather-degrading bacteria were isolated and grown in feather meal medium (basic medium) containing (g LG1): $\mathrm{K}_{2} \mathrm{HPO}_{4}$ (1.4), $\mathrm{MgSO}_{4}(0.1), \mathrm{KH}_{2} \mathrm{PO}_{4}(0.7), \mathrm{NaCl}(0.5)$, ground keratin as sole carbon and nitrogen source, and 15-20 g agar for solidification. The $\mathrm{pH}$ of this medium was adjusted to $7 \cdot 0^{9,22}$. The feather meal plates were spread with $1 \mathrm{~mL}$ diluted medium and incubated at $37^{\circ} \mathrm{C}$ for 2 days for general bacteria whereas incubation of 5-7 days was carried out for actinomycetes. Nutrient agar medium was used to maintain purified bacterial colonies at $4^{\circ} \mathrm{C}$.

\section{Screening of keratolytic bacteria}

Primary screening of keratolytic bacteria

Keratolytic bacteria were primarily screened with skimmed milk agar medium ${ }^{19}$. All the ingredients of the milk agar medium were sterilized in autoclave except milk powder. The sterile milk powder was separately added as the medium reached the tolerable temperature $(45 \circ \mathrm{C})$. The sterilized medium was poured into sterile Petri dishes. The suspected bacteria isolates, maintained in starch agar medium and nutrient agar, were inoculated in milk agar plates. The plates were incubated at $37^{\circ} \mathrm{C}$ for two days and examined for the formation of clear zones on the skimmed milk agar. The bacterial isolates exhibiting clear zone formation on the agar medium were recorded as positive. 


\section{Secondary screening of keratolytic bacteria}

The positive isolates of primary screening were subjected to secondary screening for the isolation of feather degrading bacteria. A modified basal liquid medium supplemented with a native chicken feather $(5 \mathrm{~cm})$ was placed in test tubes for secondary screening. The medium was sterilized and inoculated with selected bacterial isolates of primary screening. The test tubes were incubated at $37^{\circ} \mathrm{C}$ and examined on weekly basis for feather degradation.

\section{Identification of Bacterial Isolate BAM3}

The best keratinase-producing microorganism was identified based on cultural, morphological, and biochemical tests such as oxidase and catalase production assays. Molecular identification of the most promising isolate (BAM3) revealed it as keratinolytic Bacillus sp. BAM3. Molecular identification was carried out by extracting genomic DNA of bacteria grown to exponential phase in Luria-Bertani medium. Centrifugation of bacterial culture was carried out for $15 \mathrm{~min}$ at 12,000 rpm and supernatant (10 $\mathrm{ml}$ aliquot) was harvested. Sterile distilled water was used to wash the supernatant. Gene JET Genomic DNA Purification kit (Thermo Fisher Scientific, Massachusetts, USA) was used to extract the DNA. PCR amplification of 16SrDNA was carried out with two primers (16F27: 52 AGAGTTTGATCCTGGCTCAG 32 and 16R1522: 52 AAGGAGGTGATCCAGCCGCA 32 ) according to Buonaurio et al. ${ }^{23}$. A reaction mixture of 25 $\mu \mathrm{L}$ was prepared for the PCR amplification of the $16 \mathrm{~S}$ rRNA gene. The reaction mixture contained $12.5 \mu \mathrm{L}$ master mix $(2 \mathrm{x}), 1 \mu \mathrm{L}$ of each primer (10 pmoles/ $\mu \mathrm{l}$ ), $2 \mu \mathrm{L}$ DNA, and $9.5 \mu \mathrm{L}$ dH2O. PCR conditions were set as initial denaturation at 94 ${ }^{\circ} \mathrm{C}$ for $5 \mathrm{~min}, 35$ denaturation cycles at $94{ }^{\circ} \mathrm{C}$ for $1 \mathrm{~min}$, annealing at $55^{\circ} \mathrm{C}$ for $1 \mathrm{~min}$, extension at $72{ }^{\circ} \mathrm{C}$ for $2 \mathrm{~min}$, and a final extension at $72{ }^{\circ} \mathrm{C}$ for 10 min. Sanger sequencing of PCR samples was carried out from Beijing Genomic Institute (BGI), Hong Kong, China. BLAST software of the NCBI database was used to compare the sequences. T-Caffee algorithm (https://www.ebi.ac.uk/, EMBLEBI, Cambridgeshire, UK) was used to align the obtained sequences in Ugene ${ }^{24}$. The phylogenetic tree was constructed in an interactive tree tool iTOL (http://itol.embl.de/index. shtml) ${ }^{24}$.

\section{Keratinase Assay}

The method of Letourneau et al. ${ }^{26}$ was followed to estimate Keratinase activity by using Keratin azure substrate (Sigma-Aldrich, USA). The substrate was frozen at $-10^{\circ} \mathrm{C}$ followed by grinding into fine powder in Oscillating mil mm400 retch. Five-gram fine powder of the substrate was suspended in $1 \mathrm{ml}$ of $50 \mathrm{mM}$ Tris- $\mathrm{HCl}$ buffer $(\mathrm{pH}$ 8.0). The reaction mixture containing $1 \mathrm{ml}$ of each, crude enzyme and keratin azure suspension, was placed in a water bath at $50^{\circ} \mathrm{C}$ for $30 \mathrm{~min} .2 \mathrm{ml}$ of $0.4 \mathrm{M}$ trichloroacetic acid (TCA) was finally added to stop the reaction. The substrate was removed by centrifuging the mixture for $5 \mathrm{~min}$ at $3000 \times \mathrm{g}$. Spectrophotometry of the supernatant was carried out at $595 \mathrm{~nm}$ to measure the release of azo dye. The amount of enzyme causing 0.01 absorbance increase between the sample and control at 595 $\mathrm{nm}$ was considered as one-unit (U) of keratinase activity $^{23,25}$.

\section{Effect of $\mathrm{pH}$ and temperature on keratinase production}

The flasks were incubated at different temperatures $\left(25,30,37,45\right.$, and $\left.50^{\circ} \mathrm{C}\right)$ for 7 days at $200 \mathrm{rpm}$ to assess optimum temperature. Keratin azure was used as a substrate at optimum growth temperature, and bacterial growth and keratinase activity were measured. The effect of different $\mathrm{pH}$ on keratinase production of the selected bacterial isolate was also estimated. The medium was prepared at $\mathrm{pH} 5,6,7,8$, and 9. Different sterile feather meal broths were separately placed in $250 \mathrm{ml}$ Erlenmeyer flasks containing $50 \mathrm{ml}$ of the medium and $2 \mathrm{ml}$ of preculture of the selected bacterial culture. The flasks were incubated at $37^{\circ} \mathrm{C}$ for 7 days at $200 \mathrm{rpm}$ and bacterial growth and keratinase activity were evaluated.

\section{Preparation of bioplastic film}

The keratin-based bioplastic was prepared according to Ramakrishnan et al ${ }^{27}$ with slight modifications. Keratin solution $(100 \mathrm{ml})$ was mixed with different concentrations of glycerol $(2,5$, and $10 \mathrm{wt} \%)$ and subjected to constant magnetic stirring for $5 \mathrm{~h}$ at $60^{\circ} \mathrm{C}$. The aliquot was spread on circular aluminum weighing boat (43 $\mathrm{mm}$ diameter at top) and placed in the oven for $24 \mathrm{~h}$ at $60^{\circ} \mathrm{C}$. After $24 \mathrm{~h}$, the mixture was allowed to cool down and dry. Then, bioplastic film was 
detached from the aluminum weighing boat and labeled. The process was repeated for all glycerol concentrations.

\section{Statistical Analysis}

The experiments were performed in triplicate. Means of replicates and standard

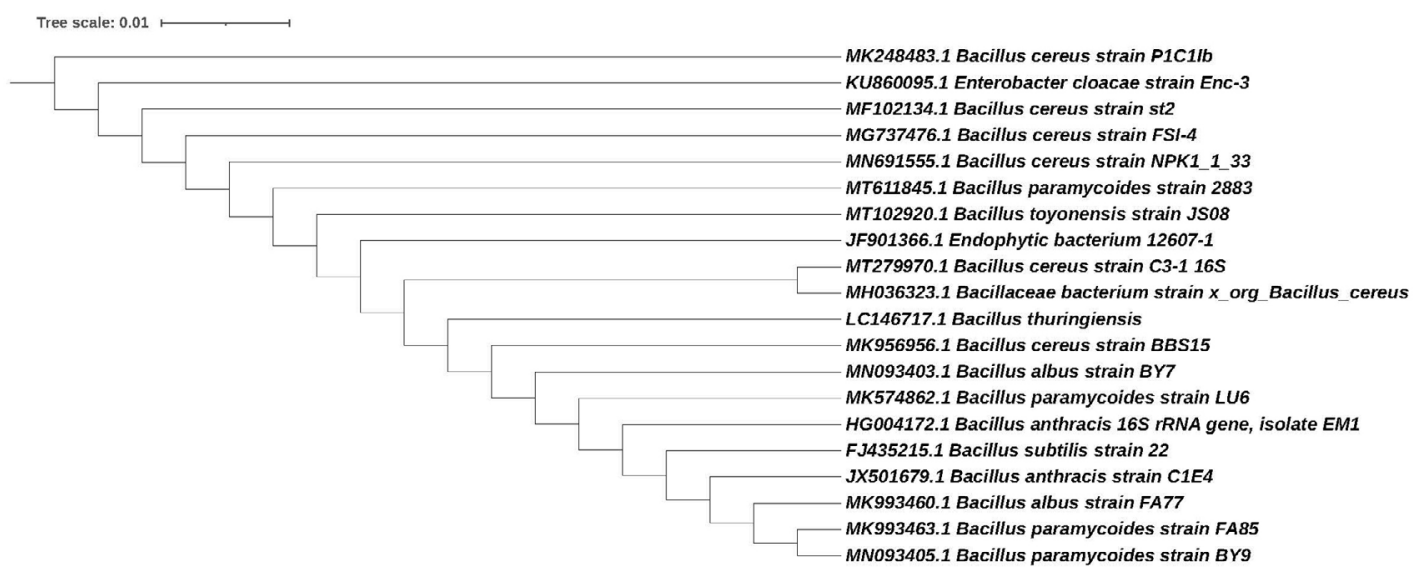

Fig. 1. Partial $16 \mathrm{~S}$ rDNA gene sequences based phylogenetic tree of Bacillus cereus BAM3 (acc. no. MK248483.1) and closely related strains

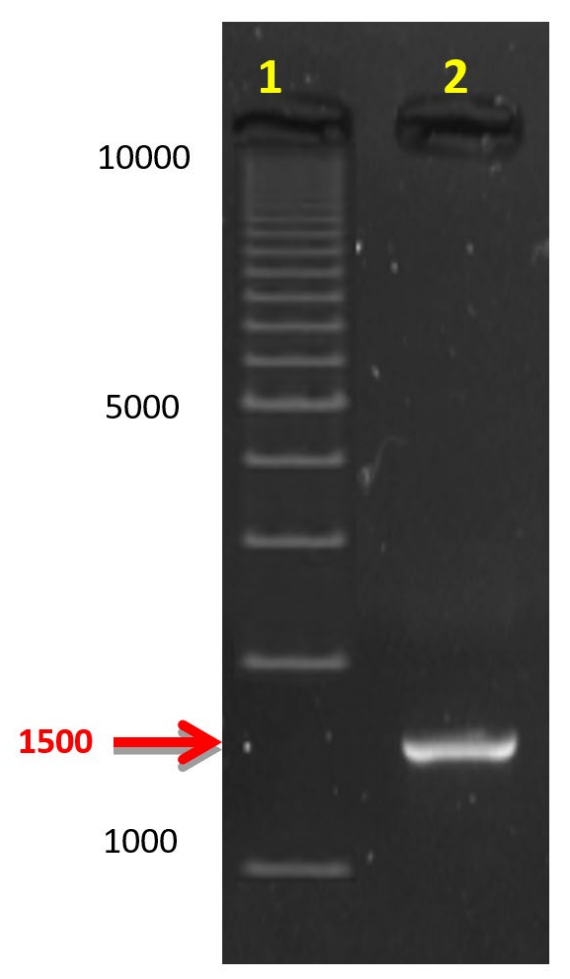

Fig. 2. The $1500 \mathrm{bp} 16 \mathrm{~S}$ rDNA amplicon separated on $0.8 \%$ agarose gel electrophoresis compared to DNA Ladder (1kb). Lane 1: 1kb DNA leader (Bio-Rad) and, Lane 2: Amplified gene from keratinolytic bacterial isolate deviation were compared by student $t$-test to differentiate between controls and treatments.

\section{RESULTS}

Fourteen bacterial isolates were found with varying levels of keratinase activity and BAM3 isolate was noted to be the most promising. The isolate was characterized as rod-shaped Grampositive bacteria with white-colored irregular rough colonies on nutrient agar plates. This bacterial isolate was identified as Bacillus sp. based on biochemical and physiological characteristics. Molecular identification revealed the phylogenetic tree of this isolate, which contains only one cluster. Bacillus sp BAM3 was more related to one strain of Enterobacter cloacae, five strains of Bacillus cereus, one strain of Bacillus thuringiensis, one strain of Bacillus toyonensis, three strains of Bacillus paramycoides, two strains of Bacillus albus, two strains of Bacillus anthracis, one strain of Endophytic bacterium, one strain of Bacillaceae bacterium, and one strain of Bacillus subtilis. The partial 16S rDNA sequencing confirmed it as Bacillus cereus BAM3 sharing 98.9-100\% identity and $100 \%$ coverage (Figure 1,2 ). 


\section{Effect of $\mathrm{pH}$ and temperature on keratinase production}

BAM3 isolate completely degraded feather within 10 days (Figure 3 ). The keratinase production was significantly higher and noted as $730 \mathrm{U} / \mathrm{ml}^{-1}$. The growth and keratinase production ability of isolate BAM3 were confirmed using one feather in mineral broth medium at an initial $\mathrm{pH}$ of 7 and $50^{\circ} \mathrm{C}$. The highest growth was noted at $37^{\circ} \mathrm{C}$ whereas optimum keratinase production was observed at $50^{\circ} \mathrm{C}$. At $50^{\circ} \mathrm{C}$, the highest level of keratinase activity (about $730 \mathrm{Uml}^{-1}$ ) was observed after $24 \mathrm{~h}$. After 7 days of growth, an increase in the medium pH (above 9) was noted (Figures 4 and 5).

\section{Preparation of bioplastic film}

At $2 \mathrm{wt} \%$ glycerol concentration, the mixture was better homogenized and depicted plasticization signs in the keratin matrix without single-phase morphology and separation. These findings are in line with the previous reports ${ }^{28}$. Undissolved particles were observed in bioplastic films at 5 and $10 \mathrm{wt} \%$ glycerol concentrations. 10 $w t \%$ glycerol bioplastic film depicted more voids and un-dissolved particles than $5 \mathrm{wt} \%$ glycerol bioplastic film. Another study ${ }^{28}$ has reported that the phase separation and formation of empty voids is directly proportional to the glycerol content (Figure 6).

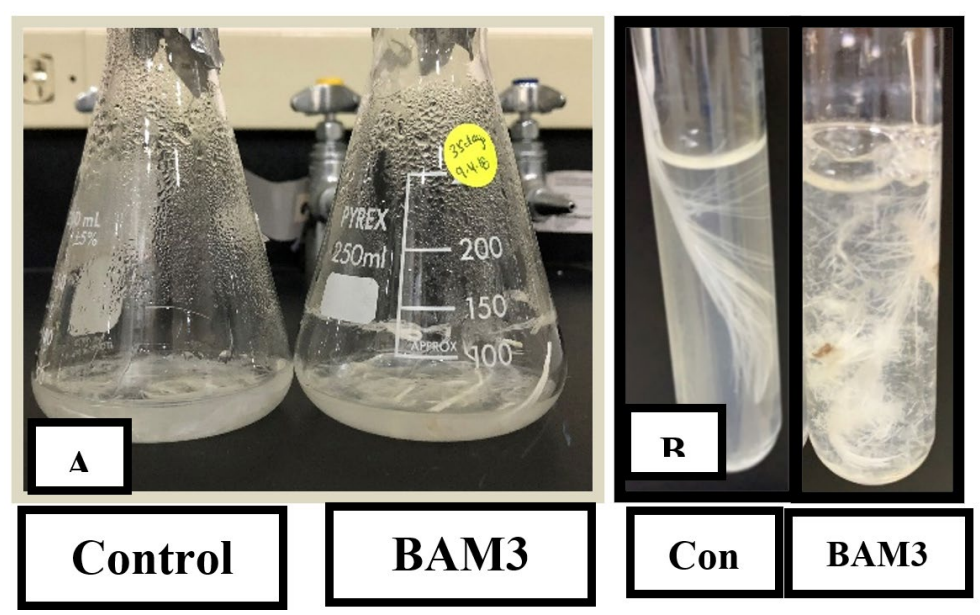

Fig. 3. (A) The flask on the left represents control whereas the flask on the right contains completely degraded feathers by bacterial isolate BAM3 after 10 days in mineral feather medium. (B) Degradation process in one row of the feather

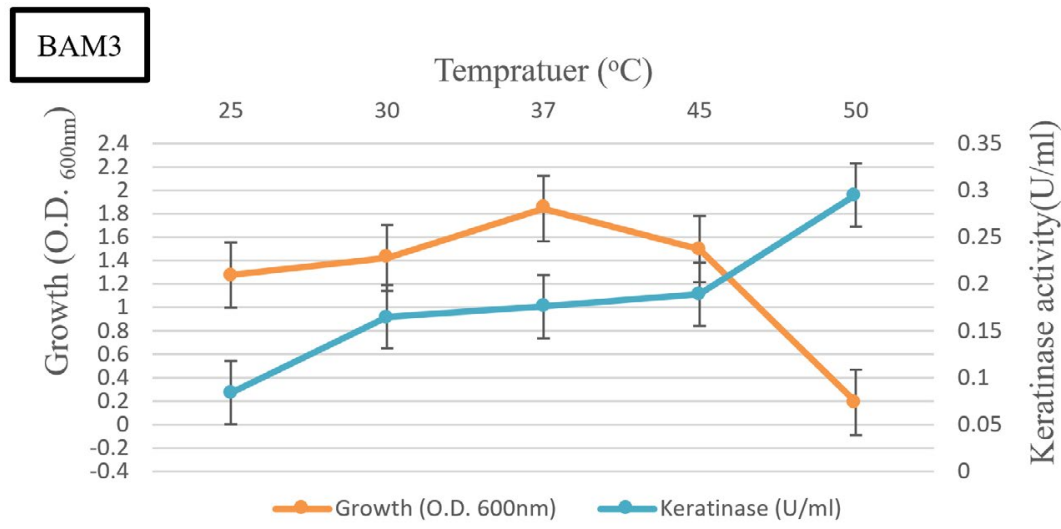

Fig. 4. The effect of temperature on the production of keratinase by isolate BAM3 

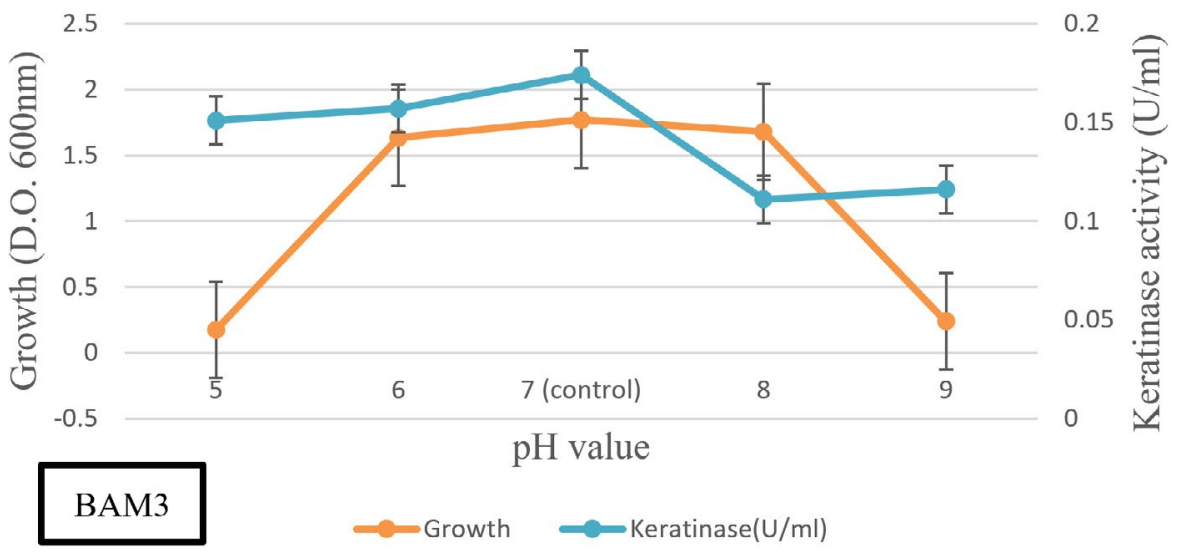

Fig. 5. The effect of $\mathrm{pH}$ on the production of keratinase by isolate BAM3
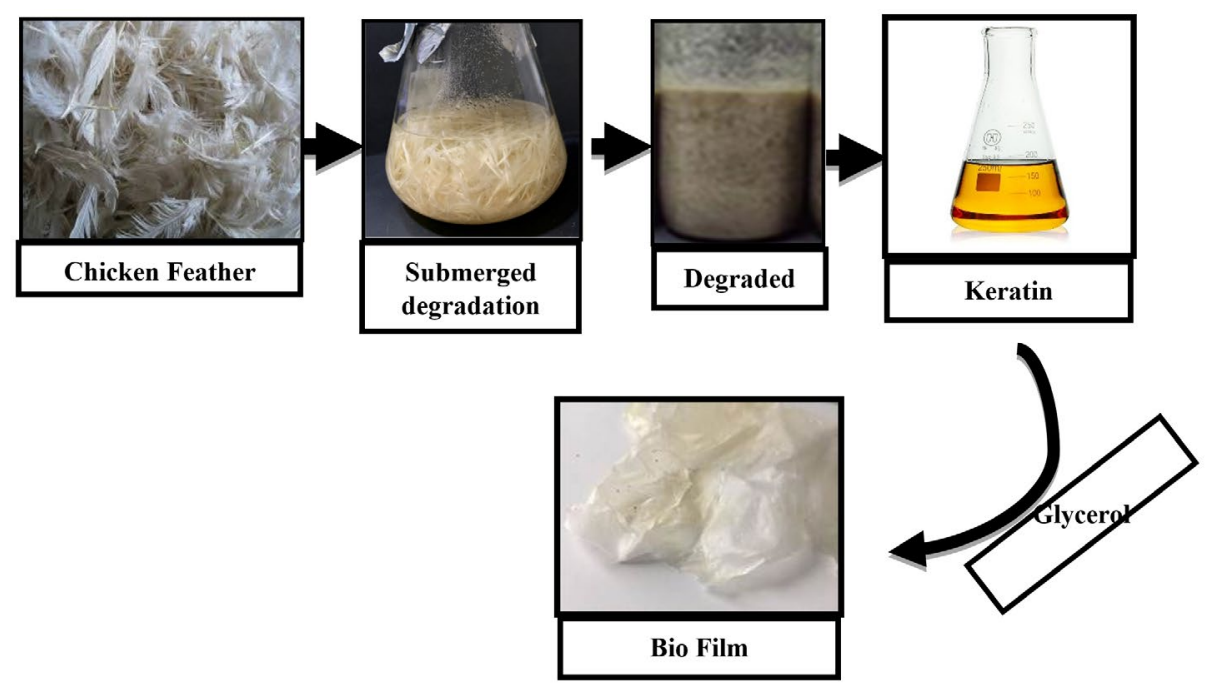

Fig. 6. Keratin-based bioplastic film derived from chicken feathers

\section{DISCUSSION}

Feather degrading keratinolytic microorganisms and keratinase enzymes could improve the digestibility of feather keratin ${ }^{9,10,11}$ to use as bioplastic ${ }^{12,13}$. A promising Keratinolytic bacterium was successfully isolated and characterized as Bacillus cereus BAM3. Some of the other isolated bacteria belonged to the Bacillus group whereas a few were Gram-negative. The findings of this study are in line with previous reports. Degradation of keratin by Gram-positive (Bacillus, Streptomyces) and Gram-negative bacteria has been reported ${ }^{14,15}$. Keratinaseproducing strain of Bacillus cereus had also been isolated ${ }^{30}$. Bacillus cereus BAM3 efficiently degraded keratin in intact feathers. Contrarily, the literature reveals the keratin degradation mostly by Bacillus cereus strains ${ }^{16}$. In this study, complete feather degradation was achieved by the aerobic growth of inoculated isolates, which used it as a primary source of nitrogen, carbon, and energy. Complete degradation of feathers in 30 days has been previously reported ${ }^{17}$. The results depict that optimized bacterial growth conditions significantly increased the keratin degradation ${ }^{18}$. The optimum bacterium growth rate temperature increased the production of a total enzyme $(730 \mathrm{U} / \mathrm{ml})$. Increased $\mathrm{pH}$ values were observed during feather degradation that is closely related to other microorganisms possessing higher keratinolytic activity ${ }^{19,31}$. The $\mathrm{pH}$ has been reported as a key factor in enzymatic feather degradation 
due to the collaborative function of keratinase and alkaline conditions. Keratin acts as a carbon and energy source for bacteria, hence a higher feather concentration might significantly enhance the growth and keratinase production ${ }^{32,33,34}$. The combination of $2 \mathrm{wt} \%$ of glycerol and keratin produced bioplastic with good surface morphology and mechanical properties. These results are comparable to the findings of Ramakrishnan et $\mathrm{a}^{27}$. They mixed extracted keratin solution with a range of glycerol solution (2-10wt\%) and found that the bioplastic film produced by $2 \mathrm{wt} \%$ glycerol possessed better mechanical and biodegradable properties ${ }^{35}$.

\section{CONCLUSION}

This study led to the successful synthesize of bioplastic by using keratin of chicken feathers. The potent Bacillus cereus BAM3 isolate could be used for the efficient biodegradation of poultry feathers. The higher concentrations of glycerol reduce maximum tensile strength in the keratin films of the chicken feathers. The results revealed that bioplastic made from $2 \mathrm{wt} \%$ glycerol and keratin had the best mechanical properties. This is a remarkable finding as these bioplastic films can substitute fossil oil-based environmentally harmful materials. The conditions optimized during this study for the growth of $B$. cereus BAM 3 isolate and release of the enzyme can facilitate the industrial production of keratinase. These conditions should be further worked out to improve the productivity of the strain and enzyme. The keratin-based bioplastic films should also be characterized to determine their thermal stability and crystallinity for successful industrial applications.

\section{ACKNOWLEDGMENTS}

None.

\section{CONFLICT OF INTEREST}

The authors declare that there is no conflict of interest.

\section{AUTHORS' CONTRIBUTION}

All authors have made a substantial, direct, and intellectual contribution to the work and approve it for publication.

\section{FUNDING}

None.

\section{DATA AVAILABILITY}

All datasets generated or analyzed during this study are included in this manuscript.

\section{ETHICS STATEMENT}

This article does not contain any studies with human participants or animals performed by any of the authors.

\section{REFERENCES}

1. Accinelli $C$, Saccà $M L$, Mencarelli $M$, Vicari A. Deterioration of bioplastic carrier bags in the environment and assessment of a new recycling alternative. Chemosphere. 2012;89:136-143. doi:10.1016/j.chemosphere.2012.05.028

2. Khot SN, Lascala JJ, Can E et al. Development and application of triglyceride-based polymers and composites. J Appl Polym Sci. 2001;82:703-723. doi:10.1002/app.1897

3. Zhang Y, Rempel C, Liu Q. Thermoplastic Starch Processing and Characteristics-A Review. Crit Rev Food Sci Nutr. 2014;54:1353-1370. doi:10.1080/104 08398.2011 .636156

4. Rocha Plácido Moore G, Maria Martelli S, Gandolfo C, José do Amaral Sobral P, Borges Laurindo J. Influence of the glycerol concentration on some physical properties of feather keratin films. Food Hydrocoll. 2006;20:975982. doi:10.1016/j.foodhyd.2005.11.001

5. Mauri AN, Añón MC. Effect of solution pH on solubility and some structural properties of soybean protein isolate films. J Sci Food Agric. 2006;86:1064-1072. doi:10.1002/jsfa.2457

6. Almeida A, Souto E. Solid lipid nanoparticles as a drug delivery system for peptides and proteins. Adv Drug Deliv Rev. 2007;59:478-490. doi:10.1016/j. addr.2007.04.007

7. Zhao R, Torley P, Halley PJ. Emerging biodegradable materials: starch- and protein-based bionanocomposites. J Mater Sci. 2008;43:3058-3071. doi:10.1007/s10853-007-2434-8

8. Reddy N, Chen L, Yang Y. Biothermoplastics from hydrolyzed and citric acid Crosslinked chicken feathers. Mater Sci Eng C. 2013;33:1203-1208. doi:10.1016/j. msec.2012.12.011

9. Dou Y, Zhang B, He M, Yin G, Cui Y. Preparation and Physicochemical Properties of Dialdehyde Starch Crosslinked Feather Keratin/PVA Composite Films. J Macromol Sci Part A. 2014;51:1009-1015. doi:10.10 80/10601325.2014.967108

10. Zhu G-Y, Zhu X, Wan X-L, et al. Hydrolysis technology and kinetics of poultry waste to produce amino acids in subcritical water. J Anal Appl Pyrolysis. 2010;88:187191. doi:10.1016/j.jaap.2010.04.005

11. Jin E, Reddy N, Zhu Z, Yang Y. Graft Polymerization of Native Chicken Feathers for Thermoplastic 
Applications. J Agric Food Chem. 2011;59:1729-1738. doi:10.1021/jf1039519

12. Mokrejs P, Svoboda P, Hrncirik J, Janacova D, Vasek V. Processing poultry feathers into keratin hydrolysate through alkaline-enzymatic hydrolysis. Waste Manag Res. 2011;29:260-267. doi:10.1177/0734242X10370378

13. Lasekan A, Abu Bakar F, Hashim D. Potential of chicken by-products as sources of useful biological resources. Waste Manag. 2013;33:552-565. doi:10.1016/j. wasman.2012.08.001

14. Sharma S, Gupta A. Sustainable Management of Keratin Waste Biomass: Applications and Future Perspectives. Brazilian Arch Biol Technol. 2016;59. doi:10.1590/1678-4324-2016150684

15. Boakye M, Rijal N, Adhikari U, Bhattarai N. Fabrication and Characterization of Electrospun PCL-MgOKeratin-Based Composite Nanofibers for Biomedical Applications. Materials (Basel). 2015;8:4080-4095. doi:10.3390/ma8074080

16. Flores-Hernández C, Colín-Cruz A, Velasco-Santos C, et al. All Green Composites from Fully Renewable Biopolymers: Chitosan-Starch Reinforced with Keratin from Feathers. Polymers (Basel). 2014;6:686-705. doi:10.3390/polym6030686

17. Khosa MA, Wu J, Ullah A. Chemical modification, characterization, and application of chicken feathers as novel biosorbents. RSC Adv. 2013;3:20800-20810. doi:10.1039/c3ra43787f

18. Saravanan S, Sameera DK, Moorthi A, Selvamurugan N. Chitosan scaffolds containing chicken feather keratin nanoparticles for bone tissue engineering. Int J Biol Macromol. 2013;62:481-486. doi:10.1016/j. ijbiomac.2013.09.034

19. Riffel A, Brandelli A. Keratinolytic bacteria isolated from feather waste. Brazilian J Microbiol. 2006;37:395-399. doi:10.1590/S1517-83822006000300036

20. Agrahari S, Wadhwa N. Degradation of chicken feather a poultry waste product by keratinolytic bacteria isolated from dumping site ay Ghazipur poultry processing plant. Int J Poult Sci. 2010; 5: 482-489. doi: 10.3923/ijps.2010.482.489

21. Tork S, Aly MM, Nawar L. Biochemical and Molecular Characterization of a New Local Keratinase Producing Pseudomomanas sp., MS21. Asian J Biotechnol. 2010;2:1-13. doi:10.3923/ajbkr.2010.1.13

22. Lin X, Lee C-G, Casale ES, Shih JCH. Purification and Characterization of a Keratinase from a FeatherDegrading Bacillus licheniformis Strain. Appl Environ Microbiol. 1992;58:3271-3275. doi:10.1128/ AEM.58.10.3271-3275.1992

23. Buonaurio R, Stravato VM, Cappelli C. Brown spot caused by Sphingomonas sp. on yellow Spanish melon fruits in Spain*. Plant Pathol. 2001;50:397-401. doi:10.1046/j.1365-3059.2001.00571.x
24. Okonechnikov K, Golosova O, Fursov M. Unipro UGENE: a unified bioinformatics toolkit. Bioinformatics. 2012;28:1166-1167. doi:10.1093/bioinformatics/ bts091

25. Letunic I, Bork P. Interactive Tree Of Life v2: online annotation and display of phylogenetic trees made easy. Nucleic Acids Res. 2011;39(suppl):W475-W478. doi:10.1093/nar/gkr201

26. Letourneau, Soussotte, Bressollier, Branland, Verneuil. Keratinolytic activity of Streptomyces sp. S .K 1-02/ : a new isolated strain. Lett Appl Microbiol. 1998;26:7780. doi:10.1046/j.1472-765X.1998.00281.x

27. Ramakrishnan N, Sharma S, Gupta A, Alashwal BY. Keratin based bioplastic film from chicken feathers and its characterization. Int J Biol Macromol. 2018;111:352358. doi:10.1016/j.ijbiomac.2018.01.037

28. Alashwal BY, Saad Bala M, Gupta A, Sharma S, Mishra P. Improved properties of keratin-based bioplastic film blended with microcrystalline cellulose: A comparative analysis. J King Saud Univ - Sci. 2020;32:853-857. doi:10.1016/j.jksus.2019.03.006

29. Fenollar O, García D, Sánchez L, López J, Balart R. Optimization of the curing conditions of PVC plastisols based on the use of an epoxidized fatty acid ester plasticizer. Eur Polym J. 2009;45:2674-2684. doi:10.1016/j.eurpolymj.2009.05.029

30. Silverajah VSG, Ibrahim NA, Yunus WMZW, Hassan HA, Woei CB. A Comparative Study on the Mechanical, Thermal and Morphological Characterization of Poly(lactic acid)/Epoxidized Palm Oil Blend. Int J Mol Sci. 2012;13:5878-5898. doi:10.3390/ijms13055878

31. Edwards A, Jarvis D, Hopkins T, Pixley S, Bhattarai N. Poly(å-caprolactone)/keratin-based composite nanofibers for biomedical applications. J Biomed Mater Res Part B Appl Biomater. 2015;103:21-30. doi:10.1002/jbm.b.33172

32. Cao L, Tan H, Liu Y, Xue X, Zhou S. Characterization of a new keratinolytic Trichoderma atroviride strain F6 that completely degrades native chicken feather. Lett Appl Microbiol. 2008;46:389-394 doi:10.1111/j.1472765X.2008.02327.x

33. Ahmadpour F, Yakhchali B, Musavi MS. Isolation and identification of a keratinolytic Bacillus cereus and optimization of keratinase production. J Appl Biotechnol Reports. 2016;3:507-512.

34. Cheng S-W, Hu H-M, Shen S-W, Takagi H, Asano M, Tsai $Y-C$. Production and Characterization of Keratinase of a Feather-degrading Bacillus licheniformis PWD-1. Biosci Biotechnol Biochem. 1995;59:2239-2243. doi:10.1271/ bbb.59.2239

35. Bach E, Daroit DJ, Corrêa APF, Brandelli A. Production and properties of keratinolytic proteases from three novel Gram-negative feather-degrading bacteria isolated from Brazilian soils. Biodegradation. 2011;22:1191-1201 doi:10.1007/s10532-011-9474-0 